\title{
DIREITO COMUNITÁRIO E SOBERANIA: ALGUMAS REFLEXÕES
}

\author{
Enrique Ricardo Lewandowski \\ Professor Associado da Faculdade de Direito da Universidade de São Paulo \\ Desembargador do Tribunal de Justiça do Estado de São Paulo
}

Resumo:

$\mathrm{O}$ artigo trata do processo de globalização que se processa neste final de século, com a formação de blocos regionais de Estados, como a União Européia, o Mercosul, o Nafta e outros, que exige uma nova perspectiva sobre o tradicional conceito de soberania.

\section{Abstract:}

The article deals with the globalization process that is taking place at the end of this century, with the creation of regional blocs of states, like the European Community, the Mercosul, the Nafta and others, that demands a new approach to the traditional concept of sovereignty.

Unitermos: União Européia; Mercosul; Nafta.

\section{Sumário:}

1. Introdução.

2. O Conceito de Soberania.

3. A União Européia.

4. O Direito Comunitário.

5. Conclusões.

1. Introdução.

O mundo contemporâneo assiste a um fenômeno sem precedentes em termos históricos. Cuida-se da formação de poderosos blocos de Estados, que se submetem a normas jurídicas comuns, objetivando coordenar as respectivas ações em face de terceiros, particularmente no campo das trocas internacionais. ${ }^{1}$ Essas novas associações não se confundem com as alianças de Estado do passado, criadas

1. V. Joseph L. Brand, "The New World Order of Regional Trading Blocs", The American University Journal of International Law and Policy, v. 8, n. 1, Fall 1992, pp. 155-181. 
para a defesa de interesses comerciais ou militares de caráter transitório ou localizado.

Com efeito, a partir da segunda metade deste século, premidos pelo medo da eclosão de uma nova guerra mundial, de conseqüências imprevisíveis, e como defesa contra a competição predatória desencadeada pela globalização da economia, os diferentes Estados, nos mais variados locais do planeta, passaram a associar-se em blocos regionais, com distintos níveis de integração, visando à unif:cação de suas atuações nas áreas comercial, industrial e agrícola e, como desdobramento natural dessa cooperação, nos planos político, diplomático e militar.

A rigor, esse fenômeno não ocorre apenas em razão da intensa circulação de bens, capitais e tecnologias através das fronteiras nacionais, com a conseqüente criação de um mercado mundial, mas também em virtude da universalização de padrões culturais e da necessidade de equacionamento comum de problemas que afetam a totalidade do planeta, como o combate à poluição ambiental, a proteção dos direitos humanos, o desarmamento nuclear e o crescimento populacional. ${ }^{2}$

Surgem, assim, os novos blocos regionais de Estados, até como mecanismo de defesa contra os efeitos perversos da globalização da economia, destacando-se, dentre outros, a União Européia (UE), o Acordo de Livre Comércio da América do Norte (Nafta), o Mercado Comum do Sul (Mercosul), a Associação das Nações do Sudoeste Asiático (Asean), todos eles tendo como base um sofisticado conjunto de regras, consubstanciadas em tratados multilaterais. Embora limitados -- salvo no caso da UE -- a objetivos essencialmente comerciais, tais acordos contêm disposições que permitem um aprofundamento das relações institucionais entre os Estados-associados, especialmente no que concerne ao Mercosul.

Convém notar que, no caso da União Européia, os objetivos são bastante ambiciosos, porquanto lá se criou uma união de caráter político, com o escopo de coordenar as ações governamentais não-só no campo econômico, como também no plano das relações exteriores, da segurança e da justiça, com o estabelecimento de normas que vinculam tanto os Estados-membros, quanto os particulares que neles vivem, o que obriga a repensar o conceito de soberania, tal como tradicionalmente compreendido.

2. Cf. Liszt Vieira, Cidadania e Globalização, Rio de Janeiro, Record, 1977, pp. 72-73. 


\section{O Conceito de Soberania.}

As noções de Direito Interno e de Direito Internacional com as quais lidamos atualmente datam de um período histórico relativamente recente, ou seja, do momento em que se desenvolve o conceito de soberania do Estado, mais precisamente a partir do século XVI de nossa era.

Sem ignorar que o Jus Civile e o Jus Gentium -- os quais regulavam, respectivamente, as relações privadas entre os antigos romanos e os contatos destes com os povos dominados, e que contam com uma elaboração doutrinária e jurisprudencial de cerca de 2.500 anos -- a verdade é que o Direito Interno, enquanto sistema de normas comportamentais, com caráter cogente, dotado de supremacia dentro de um determinado âmbito territorial, e o Direito Internacional, como um conjunto de regras de relacionamento entre Estados independentes entre si, apresentam uma prática de pouco mais de trezentos anos.

A idéia de soberania desenvolve-se, como é sabido, a partir do colapso do sistema político, social e econômico da Idade Média, ocasionado por vários fatores, dentre os quais as revoltas camponesas, que romperam o vínculo da servidão que ligava os trabalhadores à terra dos senhores feudais, as epidemias, como a peste negra, que causou o despovoamento de regiões inteiras na Europa, a Reforma Protestante, que enfraqueceu a Igreja Católica, as Cruzadas e as guerras internas, que arruinaram economicamente e eliminaram fisicamente a aristocracia dominante e, finalmente, a ascensão da burguesia -- classe social desenvolvida no interior dos burgos, as cidades muradas medievais, e que não fazia parte nem da nobreza, nem do clero e nem do campesinato --, ligada às atividades mercantis e financeiras, a qual passou a disputar o poder com os demais estamentos. ${ }^{3}$

Cidades com boas facilidades portuárias, como Veneza, Gênova, Nápoles, Amalfi, Marselha, ou localizadas em pontos estratégicos, como Bruges, Antuérpia, Bari, Pisa, Colônia, Frankfurt, Stourbridge, St. Ives, tornaram-se importantes entrepostos comerciais, sobretudo para as mercadorias vindas do Oriente, passando a gozar de autonomia política, sob o égide de lideranças burguesas. ${ }^{4}$

3. V. Henri Pirenne, História Econômica e Social da Idade Média, São Paulo, Mestre Jou, $4^{\text {a }}$ ed., 1968.

4. Sobre a ascenção econômica das cidades medievais consulte-se Leo Huberman, História da Riqueza do Homem, Rio de Janeiro, Zahar, $13^{\mathrm{a}}$ ed., 1977, especialmente o cap. V. 
$\mathrm{Na}$ sequiência desse processo, os turcos otomanos tomam Constantinopla, em 1453, forçando os europeus a buscar novas rotas comerciais pelo Ocidente, dando início, assim, às grandes navegações e à descoberta do Novo Mundo, com o que se fortalece ainda mais a burguesia comercial, do ponto de vista econômico e político.

Termina nesse momento -- ao menos oficialmente -- a ordem política medieval, iniciada cerca de mil anos antes, no ano de 476, com a invasão de Roma pelos bárbaros, colocando-se um fim àquilo que Hegel chama de poliarquia, ou seja, a multiplicidade de poderes que caracteriza a organização feudal, integrada por aristocratas, corporações de ofício, cidades independentes, congregações religiosas etc., cada qual exercendo uma parcela das competências que, atualmente, são atribuídas ao Estado, em caráter exclusivo. ${ }^{5}$

A passagem de uma poliarquia para uma monarquia -- absolutista num primeiro momento -- deveu-se, sem dúvida, à burguesia, que ansiava por uma unificação do poder político, cansada do caos social, da insegurança generalizada, da multiplicidade de leis, de jurisdições, de padrões monetários, de pesos e medidas e de tributos, que caracterizavam a ordem medieval, e que impediam ou dificultavam a livre circulação de mercadorias.

No final da Idade Média, comerciantes e financistas passam, então, a apoiar economicamente determinados reis e príncipes para que estes pudessem empalmar o poder político, especialmente com o apoio de exércitos mercenários, mediante os quais subjugam militarmente os senhores feudais e demais adversários.

No plano intelectual, surge Maquiavel, na Itália, que lança, em 1513, o livro $O$ Príncipe, sobre a arte de governar, no qual assevera que a manutenção do poder político constitui o supremo bem do Estado, sendo lícito ao governante, para a consecução de tal objetivo, deixar de observar as normas éticas às quais os cidadãos comuns estão adstritos.

Thomas Hobbes, na Inglaterra, um pouco mais tarde, em 1651, escreve o Leviatã, defendendo a tese de que os homens teriam abandonado o estado de natureza, no qual viviam numa guerra de todos contra todos, e onde levavam uma

5. Cf. Georg Wilhelm Friederich Hegel, The Philosophy of History, Chicago, Encyclopaedia Britannica, 1952, p. 342. 
vida "miserável, repugnante, brutal e breve" para viver em sociedade, sob a égide de uma autoridade, em troca de segurança. ${ }^{6}$

Nessa mesma quadra histórica, na França, Jean Bodin traz à lume a obra Os Seis Livros da República, em 1576, na qual analisa os atributos da soberania, fundada no direito divino, e classificada como um "poder absoluto $e$ perpétuo" Para o autor francês, a soberania consiste no direito de: 1 . dar leis a todos e a cada um em particular; 2. declarar a guerra e negociar a paz; 3. nomear os principais magistrados e funcionários; 4 . decidir em última instância e de conceder a graça aos condenados; 5 . cunhar moedas e de estabelecer pesos e medidas; e 6. gravar os súditos com impostos e contribuições. ${ }^{7}$

Surge, assim, o Estado soberano, cuja primeira aparição se deu sob a roupagem do absolutismo monárquico, e que passou a exercer, no plano interno, de forma monopolística, essas competências listadas por Bodin. ${ }^{8}$

Em 1648, o famoso Tratado de Paz de Westphalia põe fím à Guerra dos Trinta Anos, às lutas religiosas na Europa, e redesenha o mapa político da região, com o que passam a ser assinaladas, com precisão, as fronteiras dos Estados soberanos. Nesse momento, cristaliza-se a idéia da soberania como uma moeda de duas faces: uma interna, em que é sinônimo de supremacia, e outra externa, em que coincide com a noção de independência. ${ }^{9}$

Aparecem, assim, quase que simultaneamente, o Direito Interno e o Direito Internacional, tal qual nós os conhecemos hoje: o primeiro permitindo a aplicação das normas jurídicas estatais, com supremacia, dentro de determinado âmbito territorial, e o segundo propiciando o relacionamento independente de Estados, no plano externo.

6. Cf. Thomas Hobbes, Leviathan: Or the Matter, Forme, and Power of a Commonwealth Ecclesiasticall and Civil, London, Collier-MacMillan, s.d., pp. 100-132.

7. Cf. Juan Bodino, Los Seis Libros de la República, Madrid, Aguilar, 1973, Livro I, Cap. 10, pp. $65-73$.

8. V. sobre o assunto, H.R.S. Crossman, Biografia del Estado Moderno, México, Fondo de Cultura Econômica, 1977.

9. Sobre o conceito de soberania, consulte-se Dalmo de Abreu Dallari, Elementos de Teoria Geral do Estado, São Paulo, Saraiva, 16 a ed., 1991, pp. 63-72. 


\section{A União Européia.}

Na Europa, essa nova forma de união de Estados, como visto, adquiriu tal grau de coesão que deixou de ser uma associação com fins meramente comerciais ou econômicos, para assumir a natureza de um quase-Estado, não lhe sendo, todavia, inteiramente aplicáveis os conceitos de confederação e federação, até porque se trata de um modelo ainda inacabado, conforme observam William Nicoll e Trevor C. Salmon. ${ }^{10}$

A associação européia de Estados ligados ao bloco ocidental surgiu depois da Segunda Guerra Mundial, assentando-se em três pilares, quais sejam, a Comunidade Européia do Carvão e do Aço CECA, criada pelo Tratado de Paris, de 1951, a Comunidade Econômica Européia CEE e a Comunidade Européia da Energia Atômica CEEA, estas últimas estabelecidas pelo Tratado de Roma, de 1957. Mais tarde, em 1992, através do Tratado de Maastrich, adotou-se oficialmente a denominação União Européia, operando-se uma radical transformação na natureza da associação, na medida em que seus integrantes decidem avançar para além dos objetivos iniciais de cunho meramente econômico para conferir um caráter político à aliança.

Conquanto não seja ainda um Estado, no sentido estrito da palavra, nem mesmo uma federação, como tradicionalmente concebida, a União Européia distingue-se claramente de uma simples organização internacional pela maior sofisticação e complexidade que apresenta no tocante ao relacionamento entre seus membros. Klaus-Dieter Borchart, para definir a natureza jurídica da União Européia, emprega o conceito de supranacionalidade, observando que ela "se situa a meio caminho entre um Estado no sentido tradicional e uma organização internacional" 11

De fato, a União Européia exerce funções próprias dos Estados, em muitos aspectos, por dispor de competências relativas ao mercado e à economia, sobretudo no que concerne ao intercâmbio comercial entre os seus associados, incluindo todos os aspectos fiscais, cambiais, monetários, sociais, culturais, científicos, técnicos e ambientais relacionados com esse campo de atuação. Tais

10. Cf. Understanding the New European Community, London, Prentice Hall, 1994, pp. 306-309.

11. O ABC do Direito Comunitário, Luxemburgo, Serviço das Publicações Oficiais das Comunidades Européias, 1994, p. 12. 
atribuições são exercidas por instituições que se poderiam chamar, ainda que impropriamente, de governamentais, porquanto compreendem um poder legislativo, autoridades administrativas e órgãos jurisdicionais, a saber, o Conselho Europeu, o Parlamento Europeu, o Conselho de Ministros, a Comissão Européia, o Tribunal de Justiça e a Corte de Contas. ${ }^{12}$

O Conselho Europeu reúne, pelo menos duas vezes por ano, os chefes de Estado e de Governo dos Estados-membros, bem como o presidente da Comissão Européia, assistidos pelos ministros das Relações Exteriores, para estabelecer a política geral da União, bem como para a formulação de diretrizes ou recomendações endereçadas aos demais organismos do sistema.

O Parlamento Europeu, por sua vez, embora só exerça de forma embrionária as atribuições de um poder legislativo, conta com representantes eleitos pelo voto direto dos cidadãos dos Estados-membros. Possui, basicamente, funções de natureza consultiva, embora não-vinculantes, e de caráter fiscalizatório, com referência à Comissão Européia, detendo também poder decisório em matéria de admissão de novos membros. A partir de 1975, o Parlamento passou a ter o poder de ingerência em matéria orçamentária.

A Comissão Européia, de seu turno, é integrada por personalidades nomeadas de comum acordo pelos Estados-membros, para um mandato de cinco anos, sujeitando-se colegialmente a um voto de aprovação do Parlamento Europeu. Constitui, na verdade, o órgão executivo da Comunidade. Além de dar origem a todas as ações comunitárias, apresenta propostas legislativas ao Conselho, cabendolhe, ainda, o papel de guardiã dos tratados instituidores da União e de representante dos interesses comunitários, podendo, para tanto, interpor os recursos apropriados à defesa destes junto ao Tribunal de Justiça.

O Tribunal de Justiça é composto por um número de juízes correspondente ao de países da Comunidade, nomeados por estes de forma consensual, para um mandato de seis anos, renovável por igual período. Os juízes devem apresentar todas as características e condições exigidas nos Estados de origem para o desempenho das mais altas funções jurisdicionais. Incumbe à Corte garantir, com a mais absoluta independência, a observância das normas que integram os tratados instituidores da União, bem como das regras jurídicas emanadas dos

12. V. Jean-Louis Quermonne, Le Système Politique de L'Union Européene, Paris, Montchrestien, 1994 , p. 34 e ss. 
órgãos comunitários. ${ }^{13}$ A principal atribuição do Tribunal, convém ressaltar, além de uniformizar a interpretação do direito comum aos Estados que integram a União, consiste em atuar como verdadeira Corte Constitucional, ao confrontar as leis e normas administrativas emanadas dos órgãos comunitários com os tratados instituidores da União Européia. ${ }^{14}$

A Corte de Contas, finalmente, é integrada por um número de membros coincidente com o de integrantes da Comunidade, os quais são nomeados para um mandato de seis anos pelo Conselho, após consulta ao Parlamento Europeu, tendo por incumbência controlar a legalidade e a regularidade das receitas e despesas dos órgãos comunitários, visando a garantir a correta gestão dos recursos financeiros que lhes são confiados. Embora não possua os mesmos poderes que os órgãos congêneres dos Estados-membros, especialmente por não lhe ser facultado exercer coercitivamente os atos de fiscalização, nem punir diretamente os responsáveis por eventuais infrações, possui ampla autonomia para decidir quanto às matérias a serem investigadas e aos métodos utilizados para tanto.

Em que pesem tais características, porém, a União Européia ainda não constitui um Estado, no sentido estrito da palavra, dentre outras razões porque o arraigado nacionalismo de muitos de seus integrantes, somado ao temor de que possam perder a soberania duramente conquistada ao longo dos últimos séculos, não tem permitido uma transferência mais ampla de poderes aos órgãos comunitários, sobretudo no sentido de conferir-lhes maior autonomia no campo legislativo.

\section{O Direito Comunitário.}

Ao longo do desenvolvimento da Comunidade Européia surge, paulatinamente, um novo ramo do Direito, o Direito Comunitário, que se situa entre o Direito Interno e o Direito Internacional, sem todavia confundir-se com estes. Trata-se, com efeito, de um tertium genus.

Como se sabe, um ramo do Direito adquire foros de autonomia quando possui objeto próprio, institutos próprios, métodos próprios e princípios

13. Sobre as competências do Tribunal Europeu consulte-se Renaud Dehouse, La Court de Justice de Communautés Européenes, Paris, Montchrestien, 1994, pp. 19-38.

14. Cf. Constantinos N. Kakouris, La Cour de Justice des Communauté Européenes comme Cour Constitutionelle: Trois Observations, Ole Due et alii (org.), Festschrift für Ulrich Everling, BadenBaden, Nomos, s.d. 
informativos próprios. E essas são exatamente as características que o Direito Comunitário apresenta, e que permitem chamá-lo de novo com relação aos demais ramos e sub-ramos do Direito, segundo as diversas classificações existentes.

Como objeto, o Direito Comunitário lida com um conjunto de normas supranacionais, ou seja, um sistema de regras comuns aos Estados-membros da associação, as quais emanam de fontes próprias -- que não se confundem com aquelas que produzem o Direito Interno ou Internacional, como os parlamentos e os governos locais --, isto é, os tratados de integração (por exemplo, o de Maastrich, na Europa, e mesmo o de Assunção, na América do Sul, embora ainda em fase de consolidação de suas instituições), verdadeiras cartas constitucionais (tratadosquadro), bem como resoluções e diretrizes partidas dos órgãos comunitários, que não-vinculam apenas os Estados, mas também as pessoas jurídicas públicas e privadas, bem como os particulares.

O Direito Comunitário apresenta também institutos próprios, como o chamado reenvio prejudicial, através do qual um magistrado local, se tiver dúvida sobre a aplicabilidade e a interpretação de uma norma comunitária, pode enviar uma consulta ao Tribunal de Justiça, sediado em Luxemburgo, antes de proferir sua decisão, ${ }^{15}$ o processo por descumprimento dos tratados por parte de um EstadoMembro, os recursos de anulação de atos jurídicos emanados dos órgãos comunitários, com fundamento na sua incompetência ou na inobservância de determinada formalidade, os recursos para corrigir omissão dos agentes comunitários, quanto às obrigações assumidas, etc.

Enquanto disciplina jurídica nova, o Direito Comunitário também possui um método que lhe é próprio, empregando instrumentos gnoseológicos e hermenêuticos especiais, sem prescindir daqueles do Direito Interno e do Direito Internacional, em face de seu hibridismo, privilegiando a interpretação teleológica ou finalística. Com efeito, dada a diversidade lingüística em que os tratados instituidores da União Européia são vazados, a interpretação literal ou gramatical fica praticamente impossibilitada, emergindo a busca dos fins da integração como o método mais recomendado para se extrair o exato sentido das normas comunitárias.

15. O recurso em questão talvez seja a pedra-de-toque de todo o sistema, pois permite a aplicação do Direito Comunitário diretamente pelos Judiciários locais, sem que haja a necessidade de uma estrutura forense supranacional. Consulte-se sobre a matéria Pierre Pescatore, O Recurso Prejudicial do Artigo $177^{\circ}$ do Tratado CEE e a Cooperação do Tribunal com as Jurisdições Nacionais, Luxemburgo, Serviço das Publicações Oficiais das Comunidades Européias, 1986. 
Nesse sentido, assevera Jean-Victor Louis que o Tribunal de Justiça "privilegiou métodos funcionais de interpretação, isto é, a tomada em consideração da finalidade geral dos tratados com vista a reconstituir o seu espírito" observando ainda que, em função do objetivo perseguido, recorre ora à interpretação sistemática, ora à teleológica, "de tal forma que é quase impossível distinguir uma da outra" ${ }^{16}$

O Direito Comunitário apresenta também uma principiologia própria, sem prejuízo de se valer dos consagrados princípios gerais do Direito, como o pacta sunt servanda, o suum cuique tribuere, o ne bis in idem, o nemo inauditus damnare potest, o ad impossibilia nemo tenetur, o nemo jus ignorare censetur etc. Com efeito, os princípios da paz, da unidade, da igualdade, da liberdade, da solidariedade, da segurança, do respeito aos direitos fundamentais, da subsidiariedade, ${ }^{17}$ da proporcionalidade ${ }^{18}$ além de outros, constituem verdadeiros pilares da integração européia, configurando também balizas hermenêuticas para os seus intérpretes.

Mas talvez, dentre todos, os princípios mais importantes desse novo Direiîo sejam exatamente o da autonomia da ordem jurídica comunitária, o da cooperação entre o Direito Comunitário e o Interno e, em especial, como pedras-detoque do sistema, o da aplicabilidade direta do Direito Comunitário e o da supremacia deste sobre o Direito Interno que lhe é contrário, os quais são autoexplicativos pela própria enunciação.

Por oportuno, convém registrar que, de todas as suas características, a que mais contribui para apartar o Direito Comunitário dos demais ramos do conhecimento jurídico, tornando-o sui generis, é o fato de que as suas normas não são aplicadas por um poder central, de caráter supranacional, mas pelas autoridades administrativas e judiciárias de cada um dos integrantes do bloco regional, sem qualquer interferência direta dos órgãos comunitários, cabendo ao Tribunal de

16. A Ordem Jurídica Comunitária, Luxemburgo, Serviço das Publicações Oficiais das Comunidades Européias, $5^{\text {a }}$ ed., 1995, p. 62.

17. De acordo com a redação dada ao art. $3^{\circ}, \mathrm{B}$, do Tratado da CEE pelo Tratado da União Européia, tal axioma assim se expressa: "Nos domínios que não sejam de suas atribuiçôes exclusivas, a Comunidade intervém apenas, de acordo com " princípio da subsidiariedade, se e na medida em que os objetivos da ação encarada não possam ser suficientemente realizados pelos Estadosmembros, e possam pois, devido à dimensão ou aos efeitos da ação prevista, ser melhor alcançados ao nivel comunitário"

18. O art. $3^{\circ}, \mathrm{B}$, do Tratado da CEE enuncia ainda o princípio da proporcionalidade: "A ação $d a$ Comunidade näo deve exceder o necessário para atingir os objetivos do presente Tratado". 
Justiça dirimir e prevenir eventuais conflitos, sobretudo a partir da uniformização jurisprudencial.

\section{Conclusões.}

O Direito Comunitário, que se encontra plenamente desenvolvido no seio da União Européia, importa numa evidente flexibilização do conceito tradicional de soberania, enquanto summa potestas, no plano interno e internacional, cumprindo registrar que a sua implementação, nos demais blocos regionais, afigurase apenas uma questão de tempo, em particular no âmbito do Mercosul, enquanto associação que pretende superar o estágio de mera união aduaneira ou de zona de livre comércio, para se constituir num mercado comum, com todas as conseqüências políticas e institucionais que tal situação implica.

É interessante verificar que o Tribunal de Justiça europeu, na decisão Costa/ENEL, proferida em 15 de julho de 1964, ainda nos primórdios da organização comunitária européia, já proclamava que "ao instituírem uma Comunidade de duração ilimitada e dotada de instituições próprias, de personalidade e de capacidade jurídica, de capacidade de representação internacional e, mais particularmente, de poderes reais oriundos de uma limitação de competência ou de uma transferência de atribuições dos Estados para a Comunidade, estes limitaram, se bem que em domínios restritos, os seus direitos soberanos e criaram deste modo um corpo de normas aplicável aos seus cidadãos e a si mesmos". 19

Segundo Jean-Victor Louis, a Corte de Luxemburgo, nesse acórdão, não se refere à idéia tradicional e abstrata, quase metafísica, de soberania, derivada do pensamento político clássico, mas parte do conceito de uma soberania dividida ou partilhada ou, ainda, exercida em conjunto por vários Estados no tocante a determinadas ações de interesse comum. ${ }^{20}$

Com efeito, embora os Estados-membros da União Européia tenham renunciado a parte de suas competências legislativas em favor das instituições comunitárias, particularmente no que tange à cooperação no domínio da economia, com a corajosa adoção do princípio da supremacia das normas comunitárias sobre as internas, o certo é que eles não abdicaram de sua participação ativa no seio dos

19. Apud Jean-Victor Louis, op. cit., pp. II-12, grifos nossos.

20. Op. cit, pp. 13-15. 
órgãos deliberantes do sistema, com o que, a rigor, a sua soberania não restou vulnerada.

Na realidade, o exercício dessas competências no seio de instituições comuns, segundo Jean-Victor Louis, não traduz qualquer perda em termos de soberania, dando, ao contrário, aos seus integrantes "a possibilidade de exercer responsabilidades que, no plano nacional, se haviam tornado puramente formais para Estados independentes" 21 Ademais, conforme bem observa Klaus-Dieter Borchart, falta à União Européia "a característica da competência universal, que é própria do Estado, bem como o poder de se dotar de novas competências" 22 que permanece com exclusividade nas mãos dos associados.

Acresce-se a isso o fato de que as normas do Direito Comunitário, que emergem desse novo tipo de associação política, são aplicadas através das autoridades e instituições nacionais, posto que, como nota Giorgio Gaja, apenas os Estados são dotados de instrumentos que podem atuar sobre as pessoas físicas ou jurídicas, não possuindo a União Européia "qualquer aparato central apto a exercer um poder materialmente coercitivo". ${ }^{23}$

Assim, impõe-se a conclusão de que não há qualquer violação da soberania dos Estados que integram os novos blocos regionais, nem mesmo daqueles que fazem parte da União Européia, ocorrendo, como acima observado, mera flexibilização da idéia que tradicionalmente se construiu acerca da mesma, até porque os membros da associação podem, por força desse mesmo princípio, denunciar a qualquer momento os tratados a que aderiram, sobretudo se a sua sobrevivência estiver em jogo ou se houver alteração substancial das condições vigentes à época em que foram assinados, ainda que tenham de pagar um preço elevado por tal atitude, em termos políticos ou econômicos.

São Paulo, dezembro de 1997.

21. Idem, p. 14.

22. Op. cit., p. 11.

23. Introduzione al Diritto Comunitario, Roma, Laterza, 1996, p. 6. 